\title{
A FORMAÇÃO DA FICÇÃO CAVALEIRESCA: DO HEROÍSMO ÉPICO AO CORTESÃO (SÉCULOS XII-XIV)*
}

\section{THE FORMATION OF FICTION CHIVALROUS: THE EPIC OF HEROÍSMO CORTESÃO (AGES XII-XIV)}

\author{
Javier Roberto González ${ }^{1}$ \\ Universidad Católica Argentina - CONICET
}

\begin{abstract}
Resumo: A ficção cavaleiresca medieval, identifi- Abstract: The medieval chivalric fiction, identified cada com a matéria artúrica, reconhece, ainda no seu processo de formação, outros componentes e antecedentes que é necessário assinalar e analisar com precisão, como a épica dos cantares de gesta, a historiografia latina e o romance, a hagiografia, entre outros. Se o século XIII vê nascer as primeiras traduções da matéria artúrica francesa na $\mathrm{Pe}-$ nínsula Ibérica, o século XIV produzirá as duas with the Matter of Britain, recognizes other components and antecedents which are necessary to analyze accurately, as the epic songs of the military deeds, the Latin historiography and the romance, the hagiography, among others. The thirteenth century sees the birth of the first translations of the French Matter of Britain in the Iberian Peninsula, primeiras "novelas" vernáculas essencialmente two vernacular "novels" essentially chivalric: the cavaleirescas: o Libro del caballero Zifar e o Libro del caballero Zifar and the Amadis of Gaul. Amadis de Gaula. Este estudo analisará a confi- This study will analyze the fictional setting of chivguração ficcional do heroísmo cavaleiresco manifestada nestes romances artúricos e nas obras castelhanas fundamentais, à luz da teoria das três matrizes narrativas (cosmogônica, heroica, novelesca), em cujo marco o heroísmo épico dos cantares de gesta se define como acabadamente inscrito na matriz heroica, enquanto o heroísmo cavaleiresco-cortês apresenta uma natureza mista que o situa na transição da matriz heroica à novelesca. alrous heroism manifested in both novels as well as in the Castilian fundamental works, in the light of the theory of the three narrative matrices (cosmogonic, heroic, novelistic), in which landmark the epical heroism of the songs of military deeds is set as definitely inscribed in the heroic matrix, while the courtly-chivalric heroism presents a mixed nature that lies in the transition of the heroic matrix to the novelistic one.
\end{abstract}

Palavras-chave: heroísmo; novelas cavaleirescas; teoria das três matrizes narrativas.

Keywords: heroism; chivalric novels; theory of the three narrative matrices.

Recebido em: 22/10/2013

Aprovado em: 05/12/2014

${ }^{1}$ E-mail: depto_letras@uca.edu.ar 
Ocupar-me-ei do processo de gestação e desenvolvimento do heroísmo cavaleiresco entre os séculos XII e XIV. Dados os limites que me impõe minha específica competência profissional de filólogo e hispanista, analisarei e interpretarei tal processo com algumas inevitáveis restrições, centrando-me exclusivamente na cavalaria ficcional (não na histórica, nem na doutrinal ou jurídica), e no âmbito circunscrito à Península Ibérica, o que obriga a considerar basicamente as versões vernáculas das novelas artúricas e as duas primeiras novelas de cavalarias autóctones ${ }^{2}$, o Libro del caballero Zifar e a primitiva redação perdida do Amadis de Gaula. Certamente será indispensável, para nos referirmos a esses objetos, remontar ocasionalmente tanto ao hipotexto da cavalaria artúrica francesa como a outros antecedentes e fundadores literários não estritamente cavaleirescos (a velha épica dos cantares de gesta, a lírica trovadoresca e o código do amor cortês, as coleções de exempla), ou, inclusive, não ficcionais (o discurso da historiografia, os relatos hagiográficos, os tratados jurídicos e doutrinários da cavalaria), para postular finalmente, à guisa de conclusão, a pertinência do tipo especial de relato que chamamos heroico-cavaleiresco ou heroicocortesão, em uma zona de transição ou de mescla entre uma matriz narrativa puramente heroica e outra matriz incipientemente novelesca.

Assim como, no contexto da Grécia homérica, o ethos inteiro do heroísmo guerreiro pode encerrar-se no termo areté, o heroísmo cristão medieval, tanto em sua fase inicial dos cantares de gesta como em seu posterior desenvolvimento cortesão e cavaleiresco, define sua clave ontológica e axiológica a partir

\footnotetext{
*Texto traduzido ao português por Geraldo Augusto Fernandes.

2 Utilizamos aqui o termo novela segundo o exato significado que the corresponde em língua castelhana, o de 'relato maiormente fictício e extenso em prosa', sem atender em absoluto à improcedente pretensão de introduzir em nossa nomenclatura literária o anglicismo romance para referir a narração fictícia e extensa de aventuras maravilhosas - de cujas espécies uma seria, precisamente, a ficção cavaleiresca-, opondo-a à narração ficcional de índole realista, única à qual caberia aplicar o termo novela. Em nosso entendimento, na tradição literária hispânica este último nome abarca, com igual propriedade e licitude, tanto as narrações maravilhosas como as realistas, as de aventuras como as que não o são. Cf. DEYERMOND, Alan. The Lost Genre of Medieval Spanish Literature. Hispanic Review. Número 43, 3, 1975, p. 231-259; e GÓMEZ REDONDO, Fernando. Historia de la prosa medieval castellana II: El desarrollo de los géneros. La ficción caballeresca y el orden religioso. Madrid: Cátedra, 1999, pp. 1331-1339.
}

\section{6}


da virtude denominada proeza em espanhol e português, prouesse em francês ${ }^{3}$. O conteúdo específico dessa virtude evolui e amplia-se com o correr do tempo e com a transição do poema épico ao livro de cavalarias, mas registra um núcleo semântico invariável que remete ao seu étimo latino, o verbo prodesse, 'ser útil, aproveitar, beneficiar, servir de maneira excelente ou eminente'; trata-se assim de observar, em cada etapa de sua evolução, de que diferentes maneiras o guerreiro cristão demonstra sua utilidade ou capacidade de serviço, e, conforme a ela, como variam seus modos concretos de sobressair em excelência no exercício do ofício heroico que lhe é próprio, ou seja, na guerra, na política, na sociabilidade aristocrática. Se se examinam com cuidado os cantares de gesta franceses e castelhanos, a utilidade e a excelência do guerreiro definem-se claramente como um justo exercício da virtude vassálica relativa ao senhor, segundo os dois tipos concretos de serviço que distinguem o direito feudal, o auxilium e o consilium, quer dizer, a assistência na batalha e o conselho na corte, a guerra e a política nos termos célebres de Santo Isidoro de Sevilha, a fortitudo e a sapientia ${ }^{4}$. Porém, essa semântica restrita da virtude heroica cristã, tão clara e precisa nos poemas épicos primitivos, amplia-se já nos romans franceses de matéria clássica e troiana no século XII e, muito mais notadamente, nas novelas de cavalarias de matéria artúrica, até o ponto de acrescentar ao inicial dever de auxilium e consilium para com o senhor um novo dever, agora de serviço amoroso para com a "senhora", a dama, com o qual aquela virtude heroica inicialmente feudal se redefine como cortês. A mulher, e a par dela o vasto mundo da intimidade e da relação entre os sexos, fazem assim sua fulgurante aparição na ficção heroica e reformulam um tipo de vassalagem até então puramente masculino, até convertê-lo em outro serviço mais rico e profundo, de natureza mista masculinofeminina: os cenários para as façanhas e para a manifestação das virtudes do herói já não serão apenas a guerra e a política, mas também, junto a estas, o amor, a alcova, a festa e os jogos, formas e ocasiões, todas elas, de uma sociabi-

\footnotetext{
${ }^{3}$ Cf. MENÉNDEZ PIDAL, Ramón. Cantar de Mio Cid. Texto, gramática, vocabulario. 3. ed. Madrid: Espasa Calpe, 1954, vol. II, p. 810, art. pro.

${ }^{4}$ Cf. ALFONSO EL SABIO. Código de las Siete Partidas. In: Códigos españoles concordados y anotados. Madrid: Imprenta de La Publicidad, 1848. Partida IV, Títulos 25-26, vol. III, pp. 532554.
} 
lidade ampliada e tornada complexa ${ }^{5}$. Essa evolução e ampliação do conceito de proeza -e, por sua vez, o de heroísmo- foi possível não apenas pelos embriões evolutivos insertos na própria canção de gesta, cujos estreitos parâmetros iniciais tendem por si próprios a transbordar e a alargar-se ao ritmo da mutação do contexto histórico-social que a sustenta, como também pela decidida influência que sobre a textualidade ficcional começaram a exercer outros discursos e tradições literárias, históricas, míticas e culturais, como a historiografia e pseudohistoriografia latinas medievais, o código histórico da cavalaria e os tratados doutrinais em que este é exposto e analisado, e o fecundo corpus da lírica trovadoresca provençal, veículo do fenômeno sociocultural do amor cortês. Tratase de uma somatória de influências e componentes que, em equilibrada integração e recíproca potenciação, darão como resultado o produto mais característico dessa nova épica heroica, que, para distingui-la da antiga, chamamos cavaleiresca ou cortesã, e que, até os fins do século XII e ao longo de todo o XIII, há de plasmar-se na riquíssima floração da novela artúrica. Seu processo de gestação é bem conhecido: a partir de um conjunto de antigos mitos célticos recolhidos pelo discurso pseudocronístico de certa historiografia inglesa em língua latina, cujo mais notável resultado é a Historia Regum Britanniae de Godofredo de Monmouth, os personagens do rei Artur, da rainha Guinevere, do cavaleiro Lancelote e do mago sábio Merlim passam à ficção, em verso francês, pela mão do Roman de Brut de Wace e, sobretudo, pelas novelas de Chrétien de Troyes, quem se encarrega de incorporar à matéria a doutrina occitânica do amor cortês e os códigos da cavalaria histórica. Na linha de Chrétien, Robert de Boron reformulará a lenda incorporando nela não poucos elementos provenientes da espiritualidade cisterciense e da tradição cristã heterodoxa dos Evangelhos apócrifos, com que se associam indissoluvelmente, no imaginário poético, o mito artúrico e o poderosíssimo símbolo do Santo Graal. Será com base nos poemas narrativos de Boron que haverão de surgir, já no século XIII, os três ciclos em prosa do Pequeno San Grial - que compreende L'Estoire del Saint Graal, Merlin e Perceval-, do Gran San Grial ou Vulgata, substancial narrativa artúrica que integra cinco títulos em versões extensíssimas -Joseph d'Arimathie, Merlin, Lancelot, La Queste del Saint Graal e La mort le roi Artu-, e da Post-Vulgata,

${ }^{5}$ Cf. BURGESS, Glyn Sheridan. Contribution à l'étude du vocabulaire pré-courtois. Genève: Librairie Droz, 1970, pp. 91-93; e FLORI, Jean. La chevalerie. Paris: Édition Jean-Paul Gisserot, 1998, pp. 107-108.

\section{8}


composto somente pelo Joseph d'Arimathie, uma Suite du Merlin - único texto conservado do ciclo- e La Queste del Saint Graal fundida com La mort le roi Artu. Será precisamente este último ciclo, o da Post-Vulgata, que dará origem às versões ibéricas portuguesas e castelhanas, de crucial importância para a tarefa de reconstrução hipotética das perdidas versões francesas originais ${ }^{6}$.

A transição da velha épica dos cantares de gesta a essa nova épica cavaleiresca não é substitutiva, mas integrativa: o primitivo heroísmo centrado na guerra e nos deveres feudais não se anula nem se oblitera, mas se complementa com outro heroísmo mais sofisticado e complexo, que ao ofício da guerra e à vassalagem feudal soma as virtudes mais refinadas do amor e da cortesia. $\mathrm{O}$ campo semântico da palavra cortesia cobre, em sua acepção mais ampla, uma complexa e variada série de relações e formulações sociais, de puro corte aristocrático, fundadas em dois princípios básicos: a superioridade da dama e o consequente serviço devido a esta pelo cavaleiro, segundo os modos, tempos e condições decididos e assinalados por ela; em um sentido mais estrito, a cortesia especifica tal serviço como serviço de amor, quase idolátrico em virtude do caráter radicalmente assimétrico da relação. Outros aspectos somam-se na configuração perfeita da cortesia amatória: o segredo, a discrição, a fidelidade absoluta, a moderação, a obediência total do cavaleiro aos menores caprichos da dama. O amor cortês é por definição extramatrimonial - embora não necessariamente adúltero, segundo se tem afirmado erroneamente -, já que, por seu caráter libérrimo e pelo papel superior desempenhado pela dama, se contrapõe a esse afeto conjugal que une os esposos segundo uma expressa obrigação e uma assimetria de indício oposto, isto é, radicada na superioridade do varão. Finalmente, o amor cortês define-se pela postergação indefinida do desejo, por uma alta espiritualidade que, se bem não anula nem nega a consumação carnal, compraz-se em governá-la, discipliná-la e adiá-la de acordo com os prazos que a dama, geralmente mais madura em idade e sensatez, impõe ao jovem cavaleiro, quase sempre apenas um adolescente necessitado de uma correta educação erótica; assim, o cavaleiro roga e a dama impõe adiamentos e múltiplas provas - a distância, a ordem de executar façanhas, o desdém extremado - para fazer

${ }^{6}$ Cf. GRACIA, Paloma. El ciclo de la Post-Vulgata artúrica y sus versiones hispánicas. Voz y Letra. Número VII, 1, 1996, pp. 5-15. 
digno de si o seu amador ${ }^{7}$. A disposição com que o cavaleiro seja capaz de suportar e executar as provas que decorrem dessa árdua disciplina afetiva forma parte intrínseca de seu ethos heroico, de sua proeza, que se torna cada vez mais idealizada e espiritualizada, em grande parte também por causa da recente experiência histórica das cruzadas e do obrigatório contato com as culturas mais extraordinárias, luxuosas e desenvolvidas do Islã e de Bizâncio . Seja como for, e para além das influências factuais e culturais da Provença ou do Oriente Médio, o homem europeu ocidental está evoluindo em razão do dinamismo de sua própria cultura e de seu próprio meio histórico-geográfico: as asperezas da inicial e da alta Idade Média começam a abrandar-se, os costumes refinam-se, a fase rural do feudalismo vai paulatinamente cedendo a uma progressiva urbanização, surgem a burguesia, as universidades, o gótico. Todas essas circunstâncias implicam, pela primeira vez, uma axiologia mais centrada no individual que no coletivo, na busca de novidades do que na aceitação do estabelecido, em uma honra exclusivista de classe ou de casta aristocrática que desloca ou ao menos subordina o velho sentimento comum de nação ou de raça. Ainda que não renuncie nem possa livrar-se por completo do caráter altruísta que por força lhe impõe sua missão heroica, o cavaleiro cortês, frente ao velho guerreiro feudal, define-se antes como solitário que como solidário, e hão de ser essa solidão, essa interioridade individualista, essa nova vocação para o dinâmico e o inexplorado da busca, os elementos que determinem, para o novo heroísmo cavaleiresco, sua mais característica e peculiar circunstância vital: a aventura ${ }^{9}$. O velho herói do cantar de gesta não era, literalmente falando, um aventureiro, mas um soldado de batalhas e de exércitos; seu braço, ainda que eminente e extraordinário, somava-se a outras centenas ou milhares de braços no esforço co-

7 A fonte medieval mais importante para o conhecimento do código do amor cortês é o tratado de André Capelão (CAPELLANUS, Andreas. De amore. [Tratado sobre el amor]. Edición bilingüe latín-castellano e introducción de Inés Creixell Vidal-Quadras. Barcelona: El Festín de Esopo, 1985). Veja-se também GREEN, Otis H. Amor cortesano, em seu España y la tradición occidental: el espíritu castellano en la literatura desde El Cid hasta Calderón. 4 vols. Madrid: Gredos, 1969-1972, vol. I, pp. 94-151; LAFITTE-HOUSSAT, Jacques. Trovadores y cortes de amor. Buenos Aires: Eudeba, 1963; MARKALE, Jean. El amor cortés o la pareja infernal. Barcelona: José Olañeta Editor, 1998; e GONZÁLEZ, Javier Roberto. Amor cortés y libros de caballerías. Revista Melibea, números 1-2, 2005, pp. 37-57.

${ }^{8}$ Cf. BURGESS, Glyn Sheridan. Contribution à l'étude du vocabulaire pré-courtois. op. cit., pp. $5-7$.

${ }^{9}$ Cf. Ibid., pp. 8-15. 
mum de uma guerra coletiva e de um vasto projeto nacional, étnico ou religioso, suas façanhas inscreviam-se no seio dessa empresa geral, e seus fins e propósitos orientavam-se ab initio à realização plena dessa empresa, que, de maneira evidente, transcendia - mas não excluía - sua própria e única glorificação pessoal. Pelo contrário, o herói das novelas de cavalarias, ainda que possa ocasionalmente agregar-se a empresas coletivas ou nacionais e não deixe de atuar em batalhas e em guerras, é antes de tudo o paladino solitário que percorre os caminhos sem rumo nem propósito preestabelecido, à espera que "lhe ocorram", "lhe aconteçam" aventuras que não previu nem imaginou, muitas vezes de índole sobrenatural ou maravilhosa, cujo fim último, para além - ou aquémde qualquer razão política ou de estado, consiste na maior glória e honra do próprio cavaleiro, em seu aperfeiçoamento espiritual e moral e, consequentemente, em sua qualificação como digno sujeito do reconhecimento público de seus pares e da aceitação e favores secretos de sua amada. Trata-se, contudo, de uma aventura e uma busca que não visam somente aos bens terrenos da honra ante os pares e do amor da dama; se o heroísmo épico-feudal radicava basicamente na guerra, e o heroísmo cavaleiresco, em sua base mais ampla, integrava guerra e amor, bem podemos admitir uma realização mais estrita e elevada desse mesmo heroísmo cavaleiresco, que, em suas formulações mais idealizadas, acrescenta à guerra e ao amor um terceiro componente essencial: o misticismo. Já mencionamos Robert de Boron como seu introdutor na lenda arturiana e o Santo Graal como seu emblema mais poderoso e fecundo, como o objeto e a razão de ser da maior busca e da maior aventura da cavalaria literária medieval, segundo resulta evidente no vasto projeto da Vulgata e da Post-Vulgata. Ao exercício da guerra e do amor se adiciona, desse modo, a busca intrépida da Graça, com a qual o tipo de heroísmo próprio da cavalaria cortesã se enriquece com um tipo novo e superior de religiosidade que supera em muito aquela velha religiosidade do cantar de gesta, que se revelava bem mais elementar e primária, mais exterior, popular e coletiva. Porém, se se observar melhor, amor cortês e misticismo, mais do que duas marcas distintas da nova heroicidade cavaleiresca, constituem as duas faces de uma única nota, de uma só e única aspiração ao máximo amor, que tende quer a um objeto humano - o amor cortês -, quer a um objeto divino - o misticismo - e que encontra seus respectivos símbolos nas igualmente fugazes e excelsas figuras da dama e do Santo Graal. O amor humano ou cortês, praticado exatamente segundo suas normas e limites, educa

\section{1}


e prepara para o amor divino ou místico, ao qual conduz como ao seu coroamento natural; pelo contrário, se o amor humano ou cortês transborda, se excede ou desvia-se, termina impedindo e abortando toda possibilidade de amor divino ou místico, como exemplifica o fracasso de Lancelote na obtenção do Graal. A busca do amor humano e do divino, da dama ou do Graal constitui assim uma única e grande aventura, a aventura capital da ficção cavaleiresca em sua versão arturiana, consistindo na esforçada perseguição de uma ordem terrena conforme ao modelo celeste ${ }^{10}$, um cosmos simultaneamente político, social, cortês e religioso, que, mais do que inovador ou revolucionário, se define como restaurador de uma vaga Idade de Ouro justa e perdida, segundo assinalam insistentemente os tratados de cavalaria ao estabelecer a missão própria desta ${ }^{11}$. Em síntese, se a cavalaria é, como define Keen, "un ethos en el que elementos guerreros, aristocráticos y cristianos están fundidos", e portanto, "un modo de vida en el que podemos distinguir tres aspectos esenciales: el militar, el de la nobleza y el religioso" ${ }^{\prime 2}$, esses três elementos aparecem na discursividade ficcional da Idade Média de um modo sucessivo e integrativo: o elemento puramente militar e guerreiro é a coluna vertebral da velha épica dos cantares de gesta; logo, o elemento nobre e aristocrático, identificado com o amor cortês, define a textualidade própria da lírica trovadoresca provençal; finalmente, a novela de

10 “La proeza du chevalier consiste à oser l'aventure qui, en le jetant dans l'ordre apparent des sens et des sentiments, l'amène à la découverte d'un ordre immanent, reflet de l'ordre divin [...]. C'est à travers la prouesse, la qualité militaire essentielle, que le héros courtois vise à la conquête du temps et de l'espace, conquête qui est réalisée au moyen de l'aventure et qui entraîne inéluctablement la conquête d'un coeur féminin" (BURGESS, Glyn Sheridan.

Contribution à l'étude du vocabulaire pré-courtois, op. cit., p. 103). Para uma hermenêutica do conceito de aventura na ficção cavaleiresca hispânica e, sobretudo, em Amadis de Gaula, veja-se o breve e profundo estudo de SUAREZ PALLASA, Aquilino. Fenomenología de la obra caballeresca y Amadís de Gaula. In: ORDUNA, Lilia E. Ferrario de et alii. Nuevos estudios sobre literatura caballeresca. Barcelona-Kassel: Reichenberger, 2006, pp. 1-10.

11 "Faltó en el mundo la caridad, lealtad, justicia y verdad; empezó la enemistad, deslealtad, injuria y falsedad; y de esto se originó error y perturbación en el pueblo de Dios, que fue criado para que los hombres amasen, conociesen, honrasen, sirviesen y temiesen a Dios. Luego que comenzó en el mundo el desprecio de la justicia por haberse apocado la caridad, convino que por medio del temor volviese a ser honrada la justicia; por esto todo el pueblo se dividió en millares de hombres, y de cada mil de ellos fue elegido y escogido uno, que era el más amable, más sabio, más leal, más fuerte, de más noble ánimo, de mejor trato y crianza entre todos los demás" (LLULL, Raimundo. Libro de la orden de caballería. I, 1-2. In: CUENCA, Luis Alberto de. Floresta española de varia caballería. Madrid: Editora Nacional, s.d., p. 160).

${ }^{12}$ KEEN, Maurice. La caballería. Barcelona: Ariel, 1986, pp. 32-33. 
cavalarias de matéria artúrica, ao mesmo tempo que recolhe e integra o militarguerreiro e o aristocrático-cortês, acrescenta o elemento religioso-cristão em sua forma mais idealizada e mística, plasmando como resultado a consumação da proeza heroico-cavaleiresca.

Se a fórmula precedente vale antes de tudo para a França, na Península Ibérica o processo formativo da matéria heroico-cavaleiresca, ainda que muito semelhante, apresenta certas complexidades adicionais, pois ao ingrediente principal trazido pela matéria artúrica francesa - que, segundo se conjectura, produziu uma primeira versão vernácula em língua portuguesa já no século XIII, embora os testemunhos mais velhos conservados não antecedam o XIV ${ }^{13}$-, devem somar-se outras linhas formativas, tanto ficcionais como históricodocumentais ou jurídico-doutrinárias, que contribuem em não menor medida à peculiar configuração da novelística cavaleiresca hispânica ${ }^{14}$. Entre essas linhas formativas adicionais, por sua particular relevância no processo de gestação das duas primeiras novelas originais da Península - o Libro del caballero Zifar e Amadis de Gaula -, em igualdade de importância junto à matéria artúrica destaca-se o discurso didático-moralizante das coleções de exempla, de que o ethos heroico-cavaleiresco hispânico, segundo se manifesta nas duas novelas fundacionais mencionadas, bem pode definir-se como o cruzamento e a integração do heroísmo idealizado de cunho artúrico e a moral prática e didático-exemplar dos espelhos ou regimentos de príncipes.

Sabemos, por citações e referências de meados do século XIV, que o hoje perdido Amadis de Gaula primitivo deve ter sido escrito na primeira metade desse século, embora não faltem os que defendam uma redação ainda mais anterior, no século XIII"15; aplacadas as calorosas polêmicas da crítica do século XIX e da primeira metade do XX em torno de o idioma dessa perdida versão original ser o português ou o castelhano, e resolvida a questão a favor deste último, perdurou quase até hoje o debate em torno da condição artúrica ou não artúrica

${ }^{13}$ Cf. CASTRO, Ivo. Sobre a data da introdução na península ibérica do ciclo arturiano da PostVulgata. Boletim de Filología. Número 28, 1983, pp. 81-98.

${ }^{14}$ Cf. GÓMEZ REDONDO, Fernando. La materia caballeresca: líneas de formación. Voz y Letra. Número VII, 1, 1996, pp. 45-80.

${ }^{15}$ Cf. SUÁREZ PALLASÁ, Aquilino (ed.). RODRÍGUEZ DE MONTALVO, Garci. Amadís de Gaula, libro primero. Edición crítica de Aquilino Suárez Pallasá. Buenos Aires: Universidad Católica Argentina, 2011.

\section{3}


da obra, aspecto que só se pode analisar e decidir, lamentavelmente, através da mediação e do distanciamento que impõem a única versão completa hoje conhecida - a tardia reelaboração de Garci Rodríguez de Montalvo, de fins do século $\mathrm{XV}^{16}$ - e os escassos fragmentos de uma reelaboração intermediária, datada de circa $1420^{17}$. Se a crítica cedo se deslumbrou ante os inegáveis ornamentos arturianos da novela e inaugurou, assim, um verdadeiro - e deplorável - locus communis muito difícil de modificar ${ }^{18}$, os mais relevantes estudiosos da segunda metade do século XX dividiram-se mais equitativamente entre os que seguem rendendo tributo a esse lugar comum - María Rosa Lida de Malkiel ${ }^{19}$, Juan Bautista Avalle Arce ${ }^{20}$ e os que com maior ou menor ênfase o relativizam ou negam - Edwin Place ${ }^{21}$, Juan Manuel Cacho Blecua ${ }^{22}$. Tanto uns como outros firmaram uma expressa ou tácita identificação entre a suposta condição artúrica do Amadis e a existência, na versão primitiva, de um final trágico feito de regicídios, fratricídios, parricídios e suicídios, à maneira da catástrofe geral que arremata La mort le roi Artu, final suprimido depois por Montalvo em sua refundição. De nossa parte, aderimos decididamente à corrente antiartúrica, vendo no Amadis de Montalvo - e vislumbrando, através dele, também no primitivo apenas um arturianismo ornamental, motívico, retórico, consistindo em certos

${ }^{16}$ RODRÍGUEZ DE MONTALVO, Garci. Amadís de Gaula. Edición de Juan Manuel Cacho Blecua. 2 vols. Madrid: Cátedra, 1987-1988.

${ }^{17}$ Cf. RODRÍGUEZ MOÑINO, Antonio. El primer manuscrito del Amadís de Gaula. Noticia bibliográfica. Boletín de la Real Academia Española. Número 36, 1956, pp. 199-216; LAPESA, Rafael. El lenguaje del Amadís manuscrito. Boletín de la Real Academia Española. Número 36, 1956, pp. 219-225; MILLARES CARLO, Agustín. Nota paleográfica sobre el manuscrito del Amadís. Boletín de la Real Academia Española. Número 36, 1956, pp. 217-218.

${ }^{18}$ Cf. WILLIAMS, Grace S. The Amadís Question. Revue Hispanique. Número 21, 1909, pp. 1 167; e BOHIGAS BALAGUER, Pedro. Orígenes de los libros de caballería. In: DÍAZ Plaja, Guillermo (dir.). Historia general de las literaturas hispánicas. Barcelona: Editorial Barna, 1949, vol. I, pp. 519-541.

${ }^{19}$ El desenlace del Amadís primitivo, nos seus Estudios de literatura española y comparada. Buenos Aires: Losada, 1984, pp. 185-194.

${ }^{20}$ AMADÍS DE GAULA: el primitivo y el de Montalvo. México: Fondo de Cultura Económica, 1990, p. 101-132 et passim; El Amadís primitivo. In: Actas del Sexto Congreso Internacional de Hispanistas. Toronto, vol. VI, pp. 79-82.

${ }^{21}$ Estudio literario sobre los libros I a III. In: Amadís de Gaula. Edición y anotación por Edwin B. Place. Madrid: CSIC, 1959-1969, vol. III, pp. 921-937; ¿Montalvo autor o refundidor del Amadís IV y V? In: Homenaje a Rodríguez Moñino. Madrid: Castalia, 1966, vol. II, pp. 77-80.

${ }^{22}$ AMADÍs: heroísmo mítico cortesano. Madrid: Cupsa, 1979, pp. 347-415.

\section{4}


traços não essenciais - a magia e a maravilha, a discursividade profética, o código do amor cortês, a errância cavaleiresca e a busca como pano de fundo-, que em absoluto não alcançam postular uma substância artúrica, um sentido global que responda ao que define, em essência, a ficção arturiana: o pessimismo e o fatalismo de raiz céltica, e a tragicidade dos desenlaces argumentais, tanto coletivos como individuais - Artur, Tristão, Merlim. Em consequência, temos argumentado, em diversos trabalhos, a favor do caráter feliz do desenlace do Amadis primitivo - coincidente, de um modo geral, com o atual, da versão de Montalvo-, desenlace que, com sua solução de paz entre inimigos, reconciliação generalizada e casamentos múltiplos, define a ideologia da obra de maneira nenhuma como artúrica, mas preferivelmente como romana, segundo o modelo virgiliano e augustano do otimismo integracionista, do pacisque imponere morem,/ parcere subiectis et debellare superbos (Aen., VI, 852-853) ${ }^{23}$. Trata-se de uma solução que remete a um tipo especial de ethos heroico, que, sem negar os evidentes substratos cortesãos da proeza artúrica, vincula-os a uma ética do bom governante e do rei justo, remetendo à doutrina que, no século XIV, começava a formular-se nos espelhos de príncipes e nas coleções de apólogos e exempla destinados à educação dos jovens das famílias régias ou aristocratas. $\mathrm{O}$ heroico puro reveste-se, desse modo, com as roupagens do legal, e o argumento central da novela, desenhado em grande parte sobre a base de motivos e narremas artúricos, adquire um claro sentido didático e exemplarizante, que o torna veículo adequado a uma moral já não tão idealizada, e sim mais concreta e prática. O que ensina a novela não são apenas os princípios abstratos e altruístas da valentia, do esforço e da destreza guerreira ou da fidelidade amatória cortês, mas a conveniência, o interesse de governar conforme as leis, de respeitar os direitos dos vassalos e dos amigos, como faz Amadis, e a inconveniência de violá-los ou esquecê-los, como faz o rei Lisuarte - porque se são respeitados se triunfa, como o primeiro; se, no entanto, são violados, se fracassa, como o segundo. A grande moralidade final do perdão que o vitorioso Amadis concede ao vencido Lisuarte, e a reconciliação plena de ambos, define todo o enredo

${ }^{23}$ Cf. GONZÁLEZ, Javier Roberto. Amadís de Gaula: una historia romana. In: Studia Hispanica Medievalia IV. Buenos Aires: Universidad Católica Argentina, 1996, pp. 285-293; Un ejercicio de estructuras comparadas: Amadís de Gaula y Cirongilio de Tracia. Letras, Números 50-51, 20042005, pp. 113-161; La estructura trifuncional indoeuropea en la contrautopía Amadís-Sergas. Literatura: teoría, historia, crítica. Número 12, 2010, pp. 39-70.

\section{5}


como um processo de sucessivas quebra e restauração das leis, ao mesmo tempo que pressupõe inequivocamente uma fórmula política de governo justo e eficaz, que é aquela sobre a qual se apoiou, em seu momento, o imperium romano de Augusto, e que se propõe aqui aos príncipes cristãos como modelo a seguir. O Amadis de Gaula, sem renunciar em absoluto à sua ética heroicocortesã, integra-a assim, habilmente, em uma ética de governo que prescreve claramente os deveres do rei para com a cavalaria e a nobreza, adverte sobre os perigos que acarreta o desconhecimento desses deveres, e sanciona uma fórmula concreta e prática para evitar qualquer erro a respeito, por meio do caso exemplar de Lisuarte e Amadis. A novela, em sua totalidade, é uma disciplina regum, um exemplum de vastas proporções, como suas precedentes ou contemporâneas Calila e Dimna, Sendebar, o Libro de Patronio ou o Libro de los gatos, e isso significa um enriquecimento do paradigma heroico puramente artúrico ou cortesão mediante o acréscimo, às já mencionadas observações sobre a guerra, o amor e a religiosidade, de uma quarta nota de feição muito diferente: o cálculo político, a consideração e ponderação equilibradas do governo "possível".

Idêntica carga didática e exemplar, e também idêntica condição prática e "possibilista" da moral resultante, apresenta a outra novela fundadora da cavalaria hispânica, o Libro del caballero Zifar, cuja redação remonta a princípios do século XIV. Muito se discutiu se esta obra consiste ou não em uma pura novela de cavalarias, ou se se trata antes de um conjunto de conselhos e histórias exemplares unidas com duvidoso êxito pelo limite da história de Zifar y Robo$\mathrm{an}^{24}$. O Zifar está construído, com efeito, sobre a base de uma contínua interferência dos discursos heroico-cavaleiresco e exemplar-didático, e nele as digressões exemplarizantes, as sentenças sapienciais e os apólogos demarcados abundam de maneira infinitamente mais frequente e ostensiva do que no Amadis, a tal ponto que o próprio prólogo da obra menciona a integração do cavaleiresco e do didático como um elemento capital de sua estrutura e propósito ${ }^{25}$. Tanto o

${ }^{24}$ Uma boa síntese histórica e crítica da polêmica oferece Juan Manuel Cacho Blecua em seu artigo: El género del Zifar. (Sevilla: Cromberger, 1512). Thesaurus. Número 54, 1999, pp. 76-105.

25 "Ca por razon de la mengua de la memoria del ome fueron puestas estas cosas a esta obra, en la qual ay muy buenos enxiemplos para se saber guardar ome de yerro, sy bien quisiere beuir e vsar dellas; e ay otras razones muchas de solas en que puede ome tomar plazer" (Libro del caballero Zifar. Edición de Cristina González. Madrid: Cátedra, 1983, p. 71). A coexistência de muy buenos enxiemplos e de otras razones em que podem os homens ter prazer remete evi-

\section{6}


Amadis como o Zifar são espelhos de príncipes, discursos híbridos épicodidáticos ou novelesco-exemplarizantes, que inscrevem e rediscutem, em fórmula heterogênea, o ethos heroico cortesão da cavalaria artúrica no quadro moral e legal de uma axiologia prática, pensada para o governante sábio e eficaz ${ }^{26}$. Porém, para melhor compreender, em termos de estrita poética da narração, a evolução da proeza do cantar de gesta, da novela arturiana e desses dois primeiros livros de cavalarias hispânicos, e a concomitante mutação de um tipo de heroísmo puramente guerreiro em guerreiro-cortesão e logo em cortesão-legal, devemos enquadrar nossa análise do heroísmo cavaleiresco em um marco teórico que lhe possa conferir maior solidez conceitual do ponto de vista da narratologia. Fá-lo-emos a partir de uma hipótese de trabalho que esboçamos em trabalhos recentes ${ }^{27}$ - e que esperamos poder desenvolver mais amplamente nos próximos anos -, sob a denominação de teoria das três matrizes narrativas.

Sabemos, desde o estruturalismo clássico, que toda narração consta, em última instância e à margem de outros elementos ocasionais, secundários ou prescindíveis, pelo menos dos três seguintes: 1) um sujeito; 2) uma ação; 3) um objeto $^{28}$. Sujeito e objeto constituem os elementos invariáveis ou fixos da fábula,

dentemente à clássica fórmula horaciana do prodesse et delectare, fazendo radicar no primeiro termo a discursividade didática e, no segundo, a propriamente cavaleiresca.

${ }^{26}$ Deve-se dizer que essa integração de heroísmo cavaleiresco artúrico e axiologia do bom príncipe se consumam de maneira mais artística no Amadis, onde o elemento didático-exemplar aparece muito melhor absorvido e assimilado pela trama narrativa, e cuja ética heroica de base ainda sobrevive como mais "principista" e idealista, apesar de sua reformulação como disciplina regum, do que a moral mais claramente prática e aplicada do Zifar. "En el Zifar la exaltación del «seso natural» aplicado a las diversas situaciones conllevaba una conducta práctica, cambiante, adaptada a las circunstancias, como era habitual en el XIV en algunos de los géneros literarios seguidos. Por el contrario, los héroes de tipo amadisiano encarnaban unos valores absolutos y casi abstractos en su perfección, herederos en buena parte de la literatura artúrica". (CACHO BLECUA, Juan Manuel. El género del Zifar [Sevilla: Cromberger, 1512]. Thesaurus. Número 54, 1999, p. 103). Sem serem tão "absolutos" e "abstractos" como afirma Cacho Blecua, fica dito que os valores de Amadis combinam "principismo" e praticidade em doses mais equilibradas que o Zifar.

${ }_{27}$ Cf. GONZÁLEZ, Javier Roberto. Los «Milagros» de Berceo: alegoría, alabanza, cosmos. Buenos Aires: Miño y Dávila, 2013. Conclusiones: El milagro y el cosmos, pp. 221-250.

28 “Cada fase de la fábula -cada acontecimiento funcional- contiene tres componentes: dos actores y una acción; planteado en los términos lógicos que usa Hendricks, dos argumentos y un predicado; o, en otra formulación, dos objetos y un proceso. Lingüísticamente debería ser posible formular esta unidad como: dos componentes nominales y uno verbal. La estructura de la oración sería entonces: sujeto - predicado - objeto (directo), en la cual tanto el sujeto como el

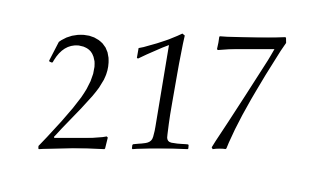


enquanto a ação encarna o elemento variável ou mutável, o "processo" 29 , de acordo com os dois níveis da história - personagens e ações - estabelecidos por Todorov $^{30}$. Já havia advertido Algirdas Greimas, em sua formulação do modelo actancial de seis componentes, que desses o sujeito e o objeto eram os actantes básicos, que definiam por sua vez a ação de base realizada em torno do semema do desejo ${ }^{31}$, isto é, em torno de um ato de vontade que põe em relação o sujeito e o objeto como o desejante e o desejado, o construtor e o construído, o possuidor e o possuído. É sobre a base dos três elementos indispensáveis de sujeito, objeto e ação, e das três maneiras diferentes de se relacionar sujeito e objeto em torno da ação, que defendemos a existência de três matrizes narrativas básicas, capazes de dar conta, segundo seu maior ou menor grau de predomínio ou incidência, da totalidade dos relatos da tradição ocidental. São elas: 1) a matriz cosmogônica, caracterizada por um sujeito que se impõe completa, absoluta e unidirecionalmente a seu objeto, cumprindo de forma acabada com as três fases de desejá-lo, construí-lo e possuí-lo, imprimindo-lhe sua forma e sua determinação; 2) a matriz heroica, em que o sujeito se impõe a seu objeto de maneira também completa, mas não já absoluta nem unidirecional, pois o objeto, por sua vez, oferece uma resistência que supõe certo grau de paixão no sujeito, de tal modo que ambos, sujeito e objeto, se modificam e se configuram reciprocamente, segundo um processo bidirecional; 3) a matriz novelesca, cujo sujeito é incapaz de determinar o objeto, ou porque não pode desejá-lo, ou porque, desejando-o, não pode construí-lo, ou porque, desejando-o e construindo-o, não pode

objeto (directo) deben ser actores, agentes de la acción". (BAL, Mieke. Teoría de la narrativa. Una introducción a la narratología. 4. ed. Madrid: Cátedra, 1995, p. 25).

${ }^{29}$ Cf. Ibid., p. 21.

${ }^{30}$ Cf. TODOROV, Tzvetan. Las categorías del relato literario. In: AA.VV. Análisis estructural del relato. Barcelona: Ediciones Buenos Aires, 1982, pp. 155-192.

31 "Es asombroso [...] que la relación entre el sujeto y el objeto [...] aparezca aquí con un investimiento semántico idéntico en los dos inventarios [de Propp y Souriau], el de 'deseo'. Parece posible concebir que la transitividad, o la relación teleológica, como hemos sugerido llamarla, situada en la dimensión mítica de la manifestación, aparezca, como consecuencia de esta combinación sémica, como un semema que realiza el efecto de sentido 'deseo'. [...] Por ejemplo, en un relato que no fuera más que una trivial historia de amor que acabara, sin la intervención de los padres, con el matrimonio, el sujeto es a la vez el destinatario, en tanto que el objeto es al mismo tiempo el destinador del amor: Él = Sujeto + Destinatario / Ella = Objeto + Destinador". (GREIMAS, Algirdas J. Semántica estructural. Investigación metodológica. $3^{\underline{a}}$ reimp. Madrid: Gredos, 1987, pp. 270-271). 
possuí-lo, de tal modo que é o objeto que agora se impõe ao sujeito, imprimindo-lhe sua forma em uma unidirecionalidade de sentido inverso à da cosmogonia. O sujeito da matriz cosmogônica é onipotente - o Deus judeu-cristão ou seus agentes delegados -, o sujeito da matriz heroica é poderoso mas limitado os deuses das mitologias, os heróis guerreiros, os santos -, e o sujeito da matriz novelesca é ou abúlico, ou impotente, ou ineficaz. Para além das mesclas que essas matrizes oferecem - poemas heroicos com componentes novelescos como a Odisseia, novelas "heroicas" como as de aventuras e as policiais -, podemos admitir, como as espécies narrativas que mais acabadamente exemplificam nossas três matrizes na Idade Média, o milagre mariano - completo relato cosmogônico, em razão da virtual onipotência de Maria, por delegação de Deus, na realização do milagre -; o cantar de gesta e a vida de santo - relatos heroicos nos quais o guerreiro ou o santo, ao mesmo tempo que imprimem no mundo uma nova "forma" a partir de um ato eficaz de vontade, vêm a sofrer de parte do mundo uma modificação que afeta sua própria subjetividade, modificação sempre melhorativa e enriquecedora -; e o apólogo ou exemplum das coleções de contos didáticos - relatos incipientemente novelescos. Quanto a esta última espécie, cumpre assinalar que a matriz novelesca procede gradualmente em sua criação, e que os modos por que o objeto-mundo se impõe ao sujeito não implicam necessariamente, para este, uma destruição ou derrota dramática, um fracasso existencial ou um abandono à abulia e à inação; tais soluções correspondem às formulações extremas da novela clássica e moderna, porém os germes matriciais novelescos consideram uma possibilidade menos cruenta: o objetomundo impõe-se ao sujeito não o fazendo fracassar ou destruindo-o, mas submetendo-o intelectual e afetivamente a suas regras, fazendo-o ver e aceitar que, para viver, é necessário adaptar-se às normas do mundo, dobrar-se a suas leis, não pretender mudá-las. É exatamente esse tipo de moral prática, “de conveniência", a que rege o mecanismo didático dos apólogos e dos exempla medievais, em clara oposição ao mecanismo heroico pelo qual sujeito e objeto se configuram e se determinam reciprocamente: o herói consegue, mediante esforço e enorme vontade, impor sua forma ao objeto - ordená-lo, melhorá-lo, resgatá-lo - e, por sua vez, o objeto modifica também o sujeito, opondo-lhe uma resistência que o fortalece, o instrui, o comove, o torna mais sábio, melhor, mais nobre.

É entre esses dois polos, correspondentes à matriz puramente heroica e à matriz novelesca em sua especificidade seminal de exemplum didático, que se

\section{9}


situam as realizações do heroísmo cavaleiresco e cortesão próprias tanto da novela artúrica quanto dos dois primeiros livros de cavalarias hispânicos, o Amadis e o Zifar. A novela artúrica e a primeira realização vernácula ibérica da novela de cavalarias definem seu peculiar ethos heroico como uma transição, uma articulação entre as matrizes singelamente heroica do cantar de gesta e seminalmente novelesca do exemplum e das coleções de apólogos, porque seus sujeitos oscilam, em sua relação com os objetos, entre uma solução de equitativa e melhorativa reconfiguração recíproca, e outra solução de sujeição unilateral voluntária ou não, consciente ou não - à forma e às normas deste mundo triunfante e inamovível que não conseguem - e às vezes nem sequer tentam - modificar com suas façanhas. Nessa zona de transição, resulta claro que a novela artúrica se situa, ainda, mais do lado da matriz heroica pura, enquanto o Zifar o faz mais do lado da novelesca em sua formulação didático-exemplar, e o Amadis ocupa um lugar equidistante entre ambas as matrizes; nos três casos, contudo, o tipo especial de heroísmo que seus sujeitos encarnam já não pode identificar-se unicamente com a pureza da matriz heroica, porque se trata de heróis que, seja por sucumbir a um fracasso pessoal, social, político - Lancelote, Artur, Tristão, Merlim -, seja por triunfar muito limitadamente e não já mediante a mera imposição de seu projeto, mas por meio de uma prudente aceitação e validação das normas morais e legais imperantes no mundo - Zifar, Roboan, Amadis, Lisuarte -, não chegam a produzir a integração recíproca e bidirecional de "formas" com esse objeto-mundo que, muito pelo contrário, se lhes impõe unidirecionalmente, seja sob a forma de um impiedoso fatum que golpeia e faz fracassar até o fim os projetos heroicos, relativizando fortemente seus triunfos parciais anteriores, conforme acontece na novela artúrica, seja sob a forma de uma norma moral e legal que os heróis aceitam e põem em obra, fazendo consistir nisso seu projeto e sua proeza, como se observa no Amadis e no Zifar. Se, apesar de tudo, ainda se conserva operativa nessas obras a base heroica da narração, é porque os sujeitos se apresentam como excepcionais e esforçados, executam façanhas que trazem parcialmente melhorias e novidades ao mundo, e a seu modo perseguem a implantação de uma ordem, ainda que ao fim essa ordem se revele como efêmera ou impossível - novela artúrica -, ou como já iniciada e operante por si mesma na legalidade vigente - Amadis, Zifar. Quando, no desenvolvimento histórico posterior da novelística ocidental, os sujeitos careçam de toda excepcionalidade, suas ações não demonstrem sequer um limitado

\section{0}


êxito efêmero ou parcial, ou não haja ação alguma que se queira executar nem ordem possível que se aspire a conseguir, a matriz heroica terá desaparecido por completo e os sucessivos modelos do herói épico ou puramente guerreiro e do herói cavaleiresco ou cortesão terão definitivamente sucumbido ante o novo sujeito da ficção moderna: o anti-herói. 